\title{
Coronary stenting in the management of myocardial ischaemia caused by muscle bridging
}

\author{
R H Stables, C J Knight, J G McNeill, U Sigwart
}

\begin{abstract}
A man of 64 was admitted for the investigation of post infarction angina. He was found to have angiographically normal coronary arteries, except for the presence of a muscle bridge in the left anterior descending coronary artery, believed to be subtending the ischaemic area. He had sustained a completed myocardial infarction in this territory 8 months before with identical findings at coronary angiography. A coronary stent was implanted in the intramyocardial segment and the patient made a good recovery with no adverse events at follow up 6 months later.
\end{abstract}

(Br Heart f 1995;74:90-92)

Keywords: muscle bridging; coronary stenting; myocardial ischaemia.

The principal branches of the coronary arteries course on the surface of the heart in the subepicardial tissue. If a length of artery runs within myocardial tissue a muscle bridge is formed. Although this abnormality is usually regarded as an incidental finding at angiography, it has been associated with myocardial ischaemia, infarction, and sudden death. ${ }^{1-7}$ Coronary artery bypass grafting, excision of the overlying muscle band, and percutaneous transluminal coronary angioplasty (PTCA) have been used to treat patients with myocardial ischaemia attributed to a muscle bridge. $^{8-10} \mathrm{We}$ present what we believe to be the first report of the use of an intracoronary stent in the management of this type of lesion.

Department of Cardiology, The Royal Brompton Hospital, London R H Stables

C J Knight

I G McNeil

U Sigwart

Correspondence to: Dr R H Stables, Department of Invasive Cardiology, The Royal Cardiology, The Royal Brompton Hospital, Sydney Street, London SW3 $6 \mathrm{~N}$ 15 February 1995

\section{Case report}

The patient was a 64 year old man transferred to our care for investigation of angina after infarction. Eight months previously he had been admitted to another cardiac unit with new onset, severe, chest pain. He was treated with streptokinase. Serial enzyme analysis and electrocardiographic (ECG) recordings confirmed the diagnosis of a non$Q$ wave myocardial infarction. Coronary angiography, which was performed 3 days after admission, showed moderate hypokinesis of the anterior wall of the left ventricle and apparently normal coronary arteries except for the presence of a myocardial bridge in the mid portion of the left anterior descending coronary artery (LAD). Systolic contraction resulted in compression of the LAD at this point, reducing the luminal diameter by $30-50 \%$. A guide wire with a manometer at its tip was advanced down the LAD but no gradient was recorded over the affected segment. The diagnostic procedure was associated with chest pain and ST segment changes. The patient was treated with $\beta$ blockers and heparin in hospital and aspirin and nifedipine after discharge.

He had a treadmill exercise tolerance test 8 weeks later when he exercised to stage 3 of the Bruce protocol without chest pain developing. The haemodynamic response was blunted and there was $2 \mathrm{~mm}$ of horizontal ST depression in leads II and III. A positron emission tomographic scan showed reduced tissue fraction in the anterolateral wall, compatible with a partial thickness infarction. The coronary vasodilator reserve was normal and there were no signs of acute ischaemia in response to a dipyridamole infusion. Medical treatment was continued.

At clinic review 4 months later he was symptom free and no further investigations were planned. A differential diagnosis of acute myocardial infarction or focal myocarditis was recorded in the case notes.

He remained well for 5 more months (until this admission) when he presented as an emergency with severe, central, crushing chest pain. The admission ECG at his local hospital showed ST segment elevation in leads V4, V5, and V6. A working diagnosis of lateral myocardial infarction was made and tissue plasminogen activator (alteplase) was given. Pain at rest continued over the next 48 hours, despite treatment with intravenous heparin and nitrates and he was transferred to our care for urgent coronary angiography.

At catheterisation the left ventricular end diastolic pressure was $21 \mathrm{~mm} \mathrm{Hg}$ and a left ventriculogram showed antero-apical hypokinesis. Subsequent comparison with the earlier study (obtained from the other cardiac centre) showed that there had been some recovery of ventricular function since his presumed first myocardial infarction.

Selective coronary angiography again showed normal coronary arteries and a myocardial bridge segment in the mid portion 
of the LAD. On this occasion this reduced the arterial luminal diameter by up to $90 \%$ during systole. A $3.5 \mathrm{~mm}$ ACS Streak balloon was advanced to the site of the lesion and inflated to a pressure of 0.5 to 1 atm. Myocardial contraction deformed the balloon despite the resistance presented by the inflation pressure.

The lesion site was pre-dilated with the same balloon using higher pressures and a half Palmaz-Schatz intracoronary stent (PS153, Johnson and Johnson Interventional Systems) was implanted. The patient seemed sensitive to coronary flow reduction. Pronounced ST segment changes and severe chest pain developed after only 10-15 seconds of coronary occlusion. Optimum stent deployment was secured with further high pressure (15 atm) inflations of a short, noncompliant Schneider Chubby balloon. An excellent angiographic result was obtained.

The post-procedural course was uneventful, with no further episodes of chest pain. Anti-anginal medications were stopped. The patient was discharged 4 days later, after stabilisation, on an anticoagulant regimen of warfarin and dipyridamole for three months and lifelong aspirin.

The patient has remained pain free for more than 6 months despite resumption of full activity, including regular tennis, which he had previously abandoned.

\section{Discussion}

The reported incidence of myocardial bridging at pathological examination, ranges from $15 \%$ to $85 \% .{ }^{11}$ Identification at angiography is much less common with a reported incidence of $0.51-2.5 \% .^{12}$ The LAD is the vessel affected in almost all cases. ${ }^{2}$ There is one report of right coronary involvement. ${ }^{13}$ The lesion is often regarded as benign though reports have linked myocardial bridging with repolarisation abnormalities, ${ }^{14}$ myocardial ischaemia, ${ }^{12}$ infarction, ${ }^{34}$ and sudden death. ${ }^{5-7}$

One pathological study was able to define two distinct types of muscle bridge. Most are superficial bridges that cross the artery transversely towards the apex of the heart and are unlikely to limit flow. In other cases a muscle bundle is seen to arise from the right ventricular apical trabeculae and surround the LAD before terminating in the interventricular septum. ${ }^{15}$ This anatomical arrangement could explain systolic twisting and compression of the artery and create the angiographic "milking effect" appearance that has been associated with symptomatic myocardial ischaemia when more than $75 \%$ luminal narrowing is seen during systole. Flow limitation will be more marked with increasing heart rate as the diastolic interval shortens.

Intravascular ultrasound techniques have recently been used to examine the nature of these dynamic stenoses. ${ }^{16}$ This study showed clear systolic compression of the bridge segments and, in addition, delayed release of compression which may reduce diastolic coronary flow and compromise vasodilator reserve. The ultrasound images also confirmed earlier pathological observations that atheromatous disease is uncommon at the site of bridging. ${ }^{17}$

Although surgery and PTCA have been used to treat patients with symptomatic myocardial bridging, ${ }^{8-10}$ stent implantation may be a more rational treatment. Bypass grafting can be avoided or delayed in cases that present, in the main, as isolated single vessel disease. Surgical resection of the muscle bundle can be complicated by the formation of scar tissue and recurrent extrinsic compression.

Lesions are usually located in the $\mathrm{LAD}$ and are easily accessible to a percutaneous intervention. The absence of atheromatous disease and the need to resist recurrent external compression suggests that deployment of an intracoronary stent should provide a better functional result than balloon angioplasty alone.

The optimum type of stent for this indication is not known. The characteristics required include a relatively high collapse pressure to resist external radial compression, some degree of flexibility, and a small gap size. The compressive force can be estimated before implantation by determining the minimum inflation pressure of an angioplasty balloon necessary to maintain full arterial patency. The long-term results will need proper evaluation because the constant stimulation of the media by rhythmic systolic compression may increase smooth muscle proliferation.

In this case the first 6 months follow up were uneventful. Further interventions with endoluminal scaffolding in cases in which myocardial bridging causes symptoms may be warranted when there is clear evidence that a functional abnormality is producing ischaemia in that vascular territory.

1 Faruqui A, Maloy W, Felner J, et al. Symptomatic myocardial bridging of coronary arteries. $A m \mathcal{F}$ Cardiol myocardial bridging

2 Noble J, Bourassa M, Petitclere R, et al. Myocardial bridging and milking effect of the left anterior descending coronary artery: Normal variant or obstructive? $A m$ $\mathcal{f C a r d i o l ~ 1 9 7 6 ; 3 7 : 9 3 3 - 9 9 . ~}$

3 Feldman AM, Baughman KL. Myocardial infarction associated with a muscle bridge. Am Heart $\mathcal{f} 1986 ; 111$ 784-7.

4 Endo M, Lee YW, Hayashi $\mathrm{H}$, et al. Angiographic evidence of myocardial squeezing accompanying tachyarrhythmia as a possible cause of myocardial infarction. Chest 1978;73:431-3.

5 Bestetti RB, Costa RS, Kazava DK, Oliveira JS. Can isolated myocardial bridging of the left anterior descending coronary artery be associated with sudden death during exercise? Acta Cardiol 1991;46:27-30.

6 Desseigne P, Tabib A, Loire R. [Myocardial bridging of the left anterior descending coronary artery and sudden death. Apropos of 19 cases with autopsy]. (in French). Arch Mal Coeur Vaiss 1991;84:511-6.

7 Feld H, Guadanino V, Hollander G, Greengart A, Lichstein E, Shani J. Exercise-induced ventricular tachycardia in association with a myocardial bridge. Chest 1991;99:1295-6.

8 Iversen S, Hake U, Mayer E, Erbel R, Diefenbach C, Oelert H. Surgical treatment of myocardial bridging causing coronary artery obstruction. Scand $\mathcal{f}$ Thorac causing coronary artery obstruction

9 Laifer LI, Weiner BH. Percutaneous transluminal coronary angioplasty of a coronary artery stenosis at the site of myocardial bridging. Cardiology 1991;79:245-8. 
10 Cappelletti A, Margonato A, Chierchia S. [Coronary angioplasty in the presence of a myocardial bridge: clinical case]. (In Italian). Cardiologia 1991;36:477-80.

11 Polachek P. Relation of myocardial bridges and loops on the coronary arteries to coronary occlusions. Am Heart $f$ $1961 ; 61: 44-52$. 12 Kramer J, Kitazume $H$, Proudfit W, Sones F. Clinical sigquent condition involving the left anterior descending artery. Am Heart f 1993;103:283-8.

13 Woldow AB, Goldstein S, Yazdanfar S. Angiographic evidence of right coronary bridging. Cathet Cardiovasc dence of right co

14 Dean JW, Mills PG. Abnormal ventricular repolarisation in association with myocardial bridging. $\mathrm{Br}$ Heart $\mathcal{f}$ 1994;71:366-7.

15 Ferreira AG, Jr, Trotter SE, Konig B, Jr, Decourt LV, Fox K, Olsen EG. Myocardial bridges: morphological and functional aspects. Br Heart f 1991;66:364-7.

$16 \mathrm{Ge} \mathrm{J}$, Erbel R, Rupprecht JH, et al. Comparison of intravascular ultrasound and angiography in the assessment of myocardial bridging. Circulation 1994;89: 1725-32.

17 Ishii T, Asuwa $\mathrm{N}$, Masuda S, Ishikawa $\mathrm{Y}$, Kiguchi $\mathrm{H}$, Shimada $K$. Atherosclerosis suppression in the left anterior descending coronary artery by the presence of a myocardial bridge: an ultrastructural study. Mod Pathol 1991;4:424-31. 